\title{
Eosinophil percentage elevation as a prognostic factor for overall survival in patients with metastatic renal cell carcinoma treated with tyrosine kinase inhibitor
}

\author{
Hong-Kai Wang ${ }^{1,2, \#, ~ F a n g-N i n ~ W a n ~}{ }^{1,2, \#}$, Wei-Jie Gu${ }^{1,2}$, Yao Zhu ${ }^{1,2}$, Bo Dai ${ }^{1,2}$, Guo-Hai \\ Shi ${ }^{1,2}$, Hai-Liang Zhang ${ }^{1,2}$, Ding-Wei Ye ${ }^{1,2}$ \\ ${ }^{1}$ Department of Urology, Shanghai Cancer Center, Fudan University, Shanghai, China \\ ${ }^{2}$ Department of Oncology, Shanghai Medical College, Fudan University, Shanghai, China \\ \#First authors \\ Correspondence to: Hai-Liang Zhang, email: zhangh1918@163.com \\ Ding-Wei Ye, email: dwyeli@163.com \\ Keywords: eosinophil percentage, metastatic renal cell carcinoma, tyrosine kinase inhibitor, prognosis, prognostic models \\ Received: January 10,2016 Accepted: September 12, $2016 \quad$ Published: September 20, 2016
}

\section{ABSTRACT}

Background: We tried to investigate the prognostic significance of post-treatment eosinophil percentage(Eo \%) in metastatic renal cell carcinoma(mRCC) patients undertaking sorafenib.

Results: The median OS for the entire sorafenib treatment period was $\mathbf{2 1 . 9}$ months (95\% CI: 17.2-25.9 months). Of the 282 mRCC patients, 101 patients experienced an elevated post-treatment Eo \% within two months. Median OS of posttreatment Eo \% elevated group and non-elevated group were 42.9 months and $\mathbf{1 6 . 8}$ months $(p=0.000)$. After adding post-treatment Eo \% into a modified MSKCC model or Heng's model, 43 and 41 patients were reclassified into favorable group, 5 and 9 patients were reclassified to intermediate group respectively.

Methods: mRCC patients treated with sorafenib from 2006 to 2015 in were evaluated. Pre- and post-treatment Eo \% were assessed. Oncologic outcomes were analyzed by overall survival and tumor response rate. Predictive parameters were assessed in a Cox proportional hazard model.

Conclusions: Our study demonstrates that an early elevation of Eo \% after sorafenib treatment is a strong predictor of good prognosis. Eo \% can be a good supplementary for prognostic models using pre-treatment parameters.

\section{INTRODUCTION}

Renal cell carcinoma(RCC) acounts for approximately $3-4 \%$ of all adult malignancies and is the third most common urogenital malignancy in China. Eventually, nearly half of these patients will develop metastatic disease with an poor outcome. Randomized controlled trials have led to the approval of several molecular-targeted agents for the treatment of metastatic RCC $[1,2,3]$. However, before the development of multiple TKIs, interleukin-2(IL-2) and interferonalfa(IFN-a) based immunotherapy is the only treatment that has been shown to improve survival in metastatic RCC(mRCC) $[4,5]$, which emphasizes the importance of host immunity in anti-tumor treatments.
So far, systemic inflammatory response markers such as C-reactive protein(CRP) and neutrophil to lymphocyte ratio(NLR) have shown significant prognostic values for $\mathrm{mRCC}$ patients $[6,7]$. However, there are concerns that nonspecific systemic inflammatory markers may be influenced by acute inflammation or infection and somehow limit their predictive values, thus new markers needed to be evaluated. Eosinophils are traditionally referred to as effector cells in allergic diseases and parasitic infections, who has diverse functions from neutrophils and lymphocytes. It is also known to have endogenous and therapy-induced host responses to cancer [8]. Previous studies have shown an improved prognosis with tumor-associated tissue eosinophilia(TATE) in various types of solid tumors. Eosinophils also have a 
role in the regulation of the immune response, through antigen presentation to $\mathrm{T}$ cells and the production and release of immunomodulatory molecules [9]. Above all, it is interesting whether eosinophil's pre-treatment and post-treatment have predictive abilities in $\mathrm{mRCC}$ patients treated with targeted therapy, or whether it can reveal the association between host immunity and clinical outcomes.

In the current study, we tried to investigate the prognostic significance of pre- and post-treatment blood eosinophil cell percentage in $\mathrm{mRCC}$ patients undertaking sorafenib.

\section{RESULTS}

\section{Patient characteristics}

The total database included 282 patients with metastatic RCC, of which 200 were male, 82 were female. The demographics and pathological features of the patients were shown in Table 1. The median age was 58 years, ranging from 19-83 years old. Clear cell RCC was present in $233(82.6 \%)$ patients, papillary RCC and sarcomatoid RCC were present in $28(9.9 \%)$ and $21(7.5 \%)$ patients. $219(77.6 \%)$ patients underwent a prior nephrectomy, of which only 3 patients had the surgery after targeted therapy. 10 underwent a prior metastasectomy and 51 patients took a prior immunotherapy.

\section{Oncologic outcomes}

The median OS for the entire sorafenib treatment period was 21.9 months (95\% CI: 17.2-25.9 months) (Figure 1). 86 patients undergone a sorafenib dose escalation, 15 exchanged to everolimus, 9 exchanged to sunitinib and 2 exchanged to bevacizumab. CR or PR was achieved in 53(18.8\%) patients, SD was achieved in $191(67.7 \%$ ) patients, PD was achieved in $38(13.5 \%)$ patients. At the end of the follow-up, 119 patients were alive with a median follow-up period of 37 months.

The mean pre- and post-treatment Eo \% were $2.06 \%$ and $4.74 \% .12(4.1 \%)$ patients had an elevated Eo $\%(>5 \%)$ before sorafenib, while after treatment $65(23 \%)$ experienced an elevated Eo \%(>5\%) within one months and $101(35.0 \%)$ patients experienced an elevated Eo $\%(>5 \%)$ within two months. Median overall survival were significantly different between post-treatment Eo $\%$ elevated group(within 2 months) and non-elevated group, the median OS were 42.9 months and 16.8 months $(\mathrm{p}=0.000)$ (Figure 2A). Median progression free survival were 14.6 months and 6.6 monhts in both groups (Figure 2B). We did a subgroup analysis of prior immunotherapy treated patients and non-clear cell RCC patients. Although the $\mathrm{p}$ value failed to reach 0.05 in these two groups, a trend is observed(Figure 2C and 2D).

Univariate analysis showed that $\mathrm{KPS} \leq 70$, absence of prior nephrectomy, disease free interval $\leq 12$ months, metastatic sites $\geq$ two, anemia, elevation of serum calcium, elevation of serum lactate dehydrogenase and posttreatment Eo $\%<5 \%$ are associated with poor prognosis. In multivariate analysis, post-treatment Eo $\%<5 \%$ continues to be an independent factor (Table 2). Pretreatment Eo \% is not associated with prognosis. $75.9 \%$, $33.0 \%$ and $5.2 \%$ patients with CR/PR, SD or PD had an elevated post-treatment Eo \%. While 24.1\%, 67\% and $92.1 \%$ patients with $\mathrm{CR} / \mathrm{PR}, \mathrm{SD}$ or $\mathrm{PD}$ experienced no elevation of eosinophils. Only $2 \%$ patients with elevated Eo $\%$ had PD, however nearly $20 \%$ patients had early PD whose Eo \% didn't elevate(Figure 3). We failed to investigate any association between post-treatment Eo \% and other blood cell parameters such as neutrophil count, lymphocyte or NLR(Table 3) (Figure 4).

\section{Model reclassification}

After adding post-treatment Eo \% into a modified MSKCC model or a modified Heng's model, patients were reclassified into new risk categories. 43 and 41 patients were reclassified into favorable group from intermediate group in the MSKCC and Heng's model respectively, 5 and 9 patients were reclassified to intermediate group from poor group respectively. There were no difference in overall survival of either three risk-groups between the original model and the modified model(Table 4)(Figure 5) (Figure 6). The C-index of the origin MSKCC and Heng's model in our cohort is 0.694 and 0.705 , when adding Eo $\%$ to the models, the $\mathrm{C}$-index turned to 0.729 and 0.733 respectively.

\section{DISCUSSION}

These results are the first to indicate that an early elevation of Eo \% post sorafenib treatment is a strong predictor of good prognosis. Eosinophil elevation can also be a predictor of tumor response to sorafenib. We also observed that post-treatment eosinophil can be a good supplement for the MSKCC and the Heng's score(which is mainly using pre-treatment parameters) to help better stratify patients into different risk groups.

Previous studies had laid much emphasis on cancer progression and host systemic inflammatory response. It is believed that increasing tumor burden or aggressive tumor biology is related to either pro-inflammatory state with over production of cytokines or diversely an immune suppression. Many pretreatment blood-based measurements of systemic inflammatory response are prognostic in patients with RCC, including NLR [6], CRP [7], MLR, GPS [12], granulocyte-to-dendritic cell (DC) ratio [11], neutrophilia [12], thrombocytosis, lymphopenia [13] and so on. CRP is a representative marker of systemic inflammatory response. It is believed that elevated CRP level predicts poorer survival of $\mathrm{mRCC}$ patients [14][7]. NLR can reflect the combined prognostic 
Table 1: Patient characteristics $(\mathrm{N}=\mathbf{2 8 2})$

\begin{tabular}{|c|c|c|}
\hline Characteristics & No. & $\%$ \\
\hline \multicolumn{3}{|l|}{ Sex } \\
\hline Male & 200 & 70.9 \\
\hline Female & 82 & 29.1 \\
\hline \multicolumn{3}{|l|}{ Age, years } \\
\hline Median & \multicolumn{2}{|c|}{57.3} \\
\hline Range & \multicolumn{2}{|c|}{$19-83$} \\
\hline \multicolumn{3}{|l|}{ MSKCC Score } \\
\hline Low & 66 & 23.4 \\
\hline Intermediate & 178 & 63.1 \\
\hline High & 38 & 13.4 \\
\hline \multicolumn{3}{|l|}{ Heng Score } \\
\hline Low & 55 & 19.5 \\
\hline Intermediate & 158 & 56.0 \\
\hline High & 69 & 24.4 \\
\hline \multicolumn{3}{|l|}{ Pathology } \\
\hline clear cell & 233 & 82.6 \\
\hline papillary & 28 & 9.9 \\
\hline sarcomatoid & 21 & 7.5 \\
\hline \multicolumn{3}{|l|}{ Metastatic Sites } \\
\hline 1 & 131 & 46.5 \\
\hline 2 & 106 & 37.6 \\
\hline 3 & 34 & 12.1 \\
\hline$\geq 4$ & 8 & 2.8 \\
\hline Prior nephrectomy & 219 & 77.6 \\
\hline Prior metastasectomy & 10 & 3.5 \\
\hline Prior immunotherapy & 51 & 18.1 \\
\hline \multicolumn{3}{|l|}{ Best response } \\
\hline $\mathrm{CR} / \mathrm{PR}$ & 53 & 18.8 \\
\hline SD & 191 & 67.7 \\
\hline $\mathrm{PD}$ & 38 & 13.5 \\
\hline $\begin{array}{l}\text { eosinophil }>5 \% \text { before } \\
\text { treatment }\end{array}$ & 12 & 4.1 \\
\hline $\begin{array}{l}\text { eosinophil }>5 \% \text { in } 1 \text { month } \\
\text { of treatment }\end{array}$ & 65 & 23.0 \\
\hline $\begin{array}{l}\text { eosinophil }>5 \% \text { in } 2 \text { months } \\
\text { of treatment }\end{array}$ & 101 & 35.0 \\
\hline
\end{tabular}




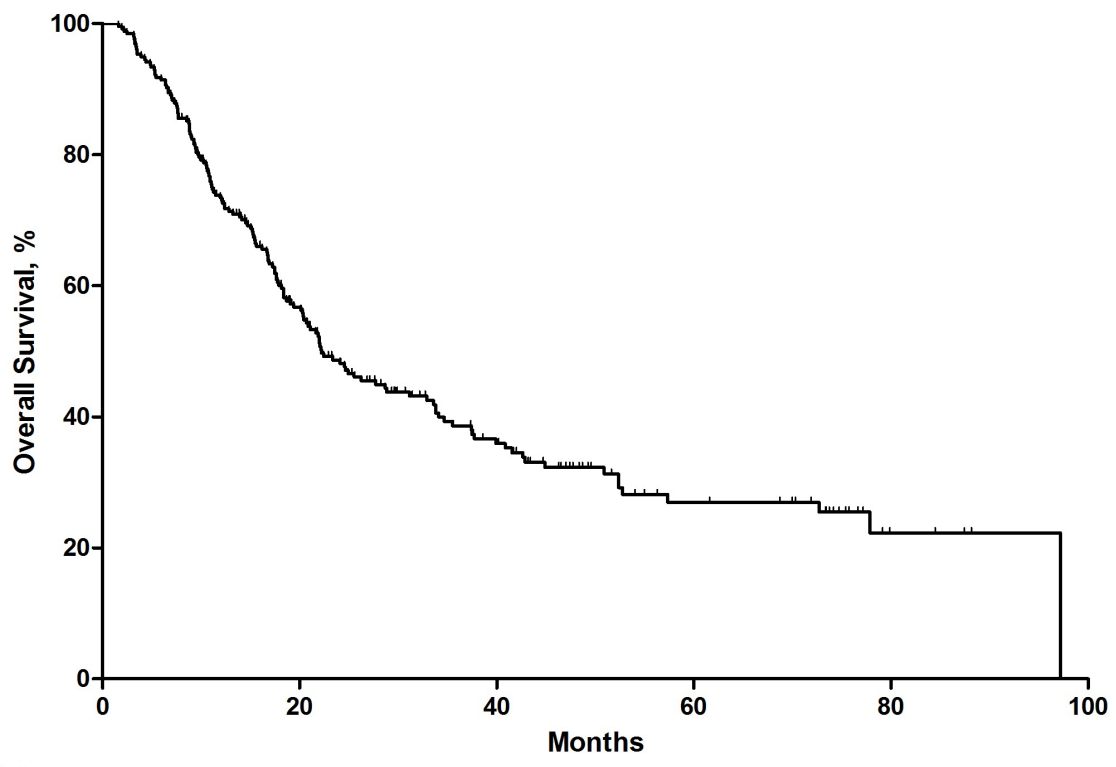

No. at risk

Figure 1: Overall survival for total patients with metastatic renal cell carcinoma.
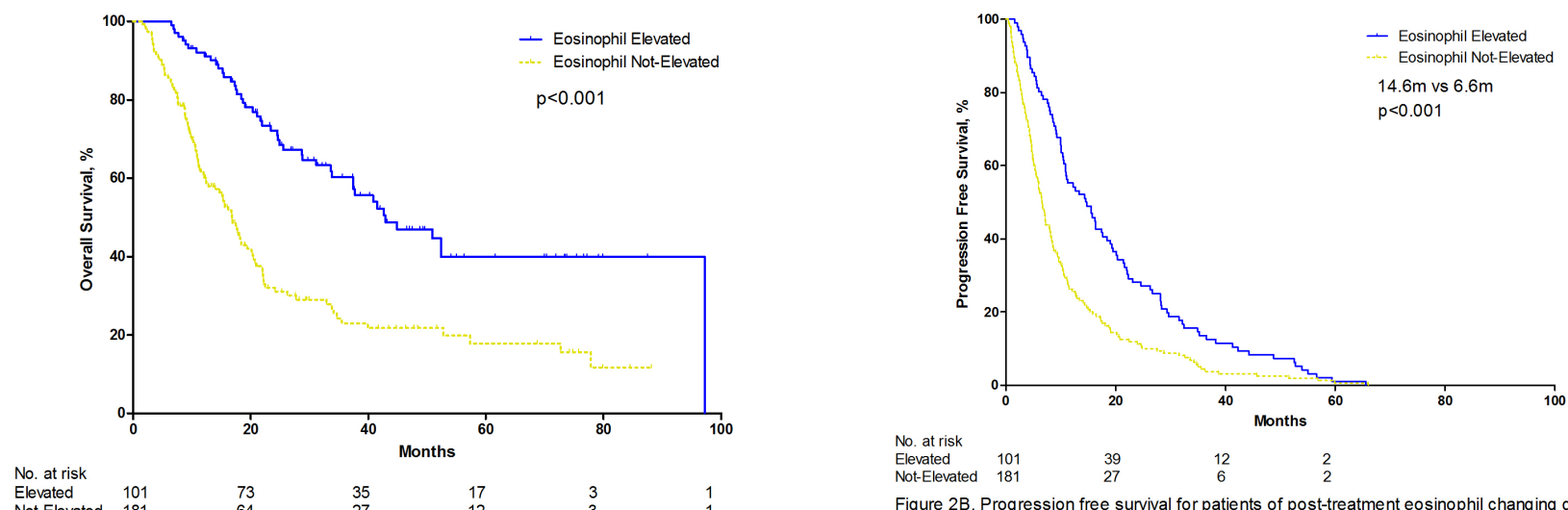

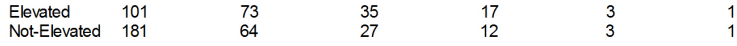

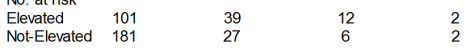

Figure $2 \mathrm{~A}$. Overall survival for total patients of different post-treatment eosinophil changing groups.

Figure 2B. Progression free survival for patients of post-treatment eosinophil changing groups.
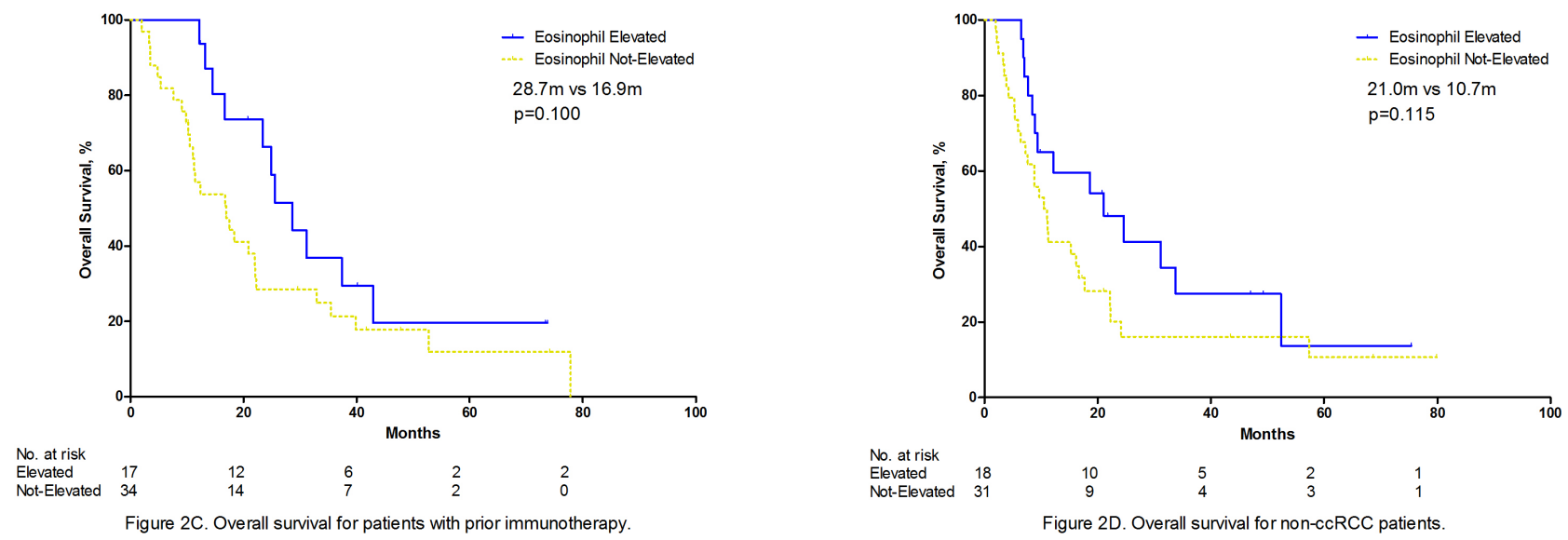

Figure 2: A. Overall survival for total patients of different post-treatment eosinophil changing groups. B. Progression free survival for patients of post-treatment eosinophil changing groups. C. Overall survival for patients with prior immunotherapy. D. Overall survival for non-ccRCC patients. 
Table 2: Univariate and multivariate analysis for overall survival in patients with mRCC

\begin{tabular}{|c|c|c|c|c|c|c|c|}
\hline \multirow[b]{2}{*}{ Characteristics } & \multirow[b]{2}{*}{ Category } & \multicolumn{3}{|c|}{ Univariate analysis } & \multicolumn{3}{|c|}{ Multivariate analysis } \\
\hline & & OR & (95\% C.I.) & $p$ value & OR & (95\% C.I.) & p value \\
\hline Gender & Male vs Female & 0.72 & $0.82-1.65$ & 0.398 & - & - & - \\
\hline Age, years & $<64$ vs $>64$ & 0.82 & $0.57-1.19$ & 0.289 & - & - & - \\
\hline KPS & $>70$ vs $\leq 70$ & 4.39 & $2.93-6.58$ & 0.000 & 2.71 & $1.68-4.19$ & 0.000 \\
\hline $\begin{array}{l}\text { Prior } \\
\text { Nephrectomy }\end{array}$ & No vs Yes & 0.68 & $0.46-0.99$ & 0.045 & 1.54 & $1.00-2.38$ & 0.017 \\
\hline $\begin{array}{l}\text { Disease Free } \\
\text { Interval }\end{array}$ & $>12 \mathrm{mo} \mathrm{vs} \leq 12 \mathrm{mo}$ & 2.76 & $1.90-3.99$ & 0.000 & 2.21 & $1.51-3.39$ & 0.000 \\
\hline Metastatic sites & $1 \mathrm{vs} \geq 2$ & 1.99 & $1.61-2.47$ & 0.000 & 1.68 & $1.34-2.11$ & 0.000 \\
\hline $\begin{array}{l}\text { Prior } \\
\text { Immunotherapy }\end{array}$ & No vs Yes & 1.41 & $1.00-2.08$ & 0.052 & - & - & - \\
\hline Anemia & No vs Yes & 2.3 & $1.67-3.18$ & 0.000 & 1.71 & $1.20-2.40$ & 0.003 \\
\hline Calcium & $<2.5 \mathrm{vs} \geq 2.5 \mathrm{mmol} / \mathrm{L}$ & 2.08 & $1.17-3.68$ & 0.012 & 1.73 & $0.92-3.24$ & 0.088 \\
\hline $\begin{array}{l}\text { Lactate } \\
\text { Dehydrogenase }\end{array}$ & $<450 \mathrm{vs} \geq 450 \mathrm{U} / \mathrm{L}$ & 4.93 & $2.46-9.81$ & 0.000 & 3.5 & $1.91-8.02$ & 0.001 \\
\hline $\begin{array}{l}\text { Neutrophil } \\
\text { Count }\end{array}$ & $\begin{array}{l}<4.5 \text { vs } \geq 4.5 \\
\quad \times 10^{\wedge} 9 / \mathrm{L}\end{array}$ & 2.06 & $1.46-2.92$ & 0.000 & 1.24 & $0.86-1.79$ & 0.247 \\
\hline Platelet Count & $\begin{array}{l}<300 \text { vs } \geq 300 \\
\quad \times 10^{\wedge} 12 / \mathrm{L}\end{array}$ & 2.62 & $1.79-3.83$ & 0.000 & 1.18 & $0.75-1.85$ & 0.467 \\
\hline $\begin{array}{l}\text { pre-treatment } \\
\text { eosinophil \% }\end{array}$ & $<5 \%$ vs $\geq 5 \%$ & 0.6 & $0.22-1.62$ & 0.315 & - & - & - \\
\hline $\begin{array}{l}\text { post-treatment } \\
\text { eosinophil } \%\end{array}$ & $<5 \%$ vs $\geq 5 \%$ & 0.37 & $0.26-0.53$ & 0.000 & 0.51 & $0.36-0.75$ & 0.000 \\
\hline
\end{tabular}

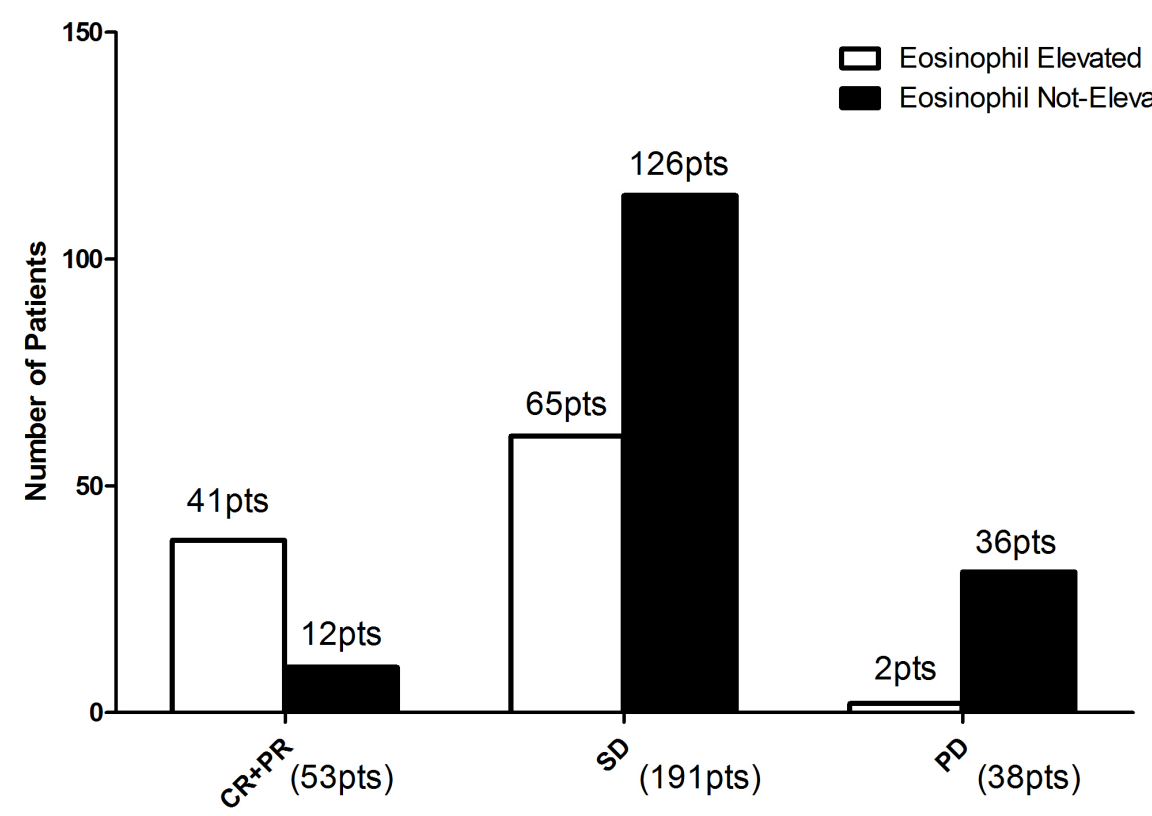

Best Response to Target Therapy

Figure 3: Best response to target therapy for patients of different eosinophil changing groups. 
Table 3: Post-Treatment eosinophil\% and its association with other post treatment hematologic parameters

\begin{tabular}{lccccc}
\hline & & \multicolumn{2}{c}{ Post-Treatment Eosinophil\% status } \\
\cline { 4 - 5 } \multicolumn{1}{c}{ Characteristics } & Category & No. of Patients & Not-171 & N=111 & p-value \\
\cline { 4 - 5 } Neutrophil Count & $\geq 4.5 \times 10^{\wedge} 9 / \mathrm{L}$ & 64 & 46 & 18 & 0.062 \\
& $<4.5 \times 10^{\wedge} 9 / \mathrm{L}$ & 218 & 125 & 93 & 0.92 \\
Lymphocyte & $\geq 0.8 \times 10^{\wedge} 9 / \mathrm{L}$ & 263 & 160 & 103 & \\
Post-treatment NLR & $<0.8 \times 10^{\wedge} 9 / \mathrm{L}$ & 19 & 11 & 8 & 0.631 \\
& $<3$ & 190 & 114 & 87 & \\
\hline
\end{tabular}

**Patients with elevated pre-treatment eosinophils were characterized to elevated group.

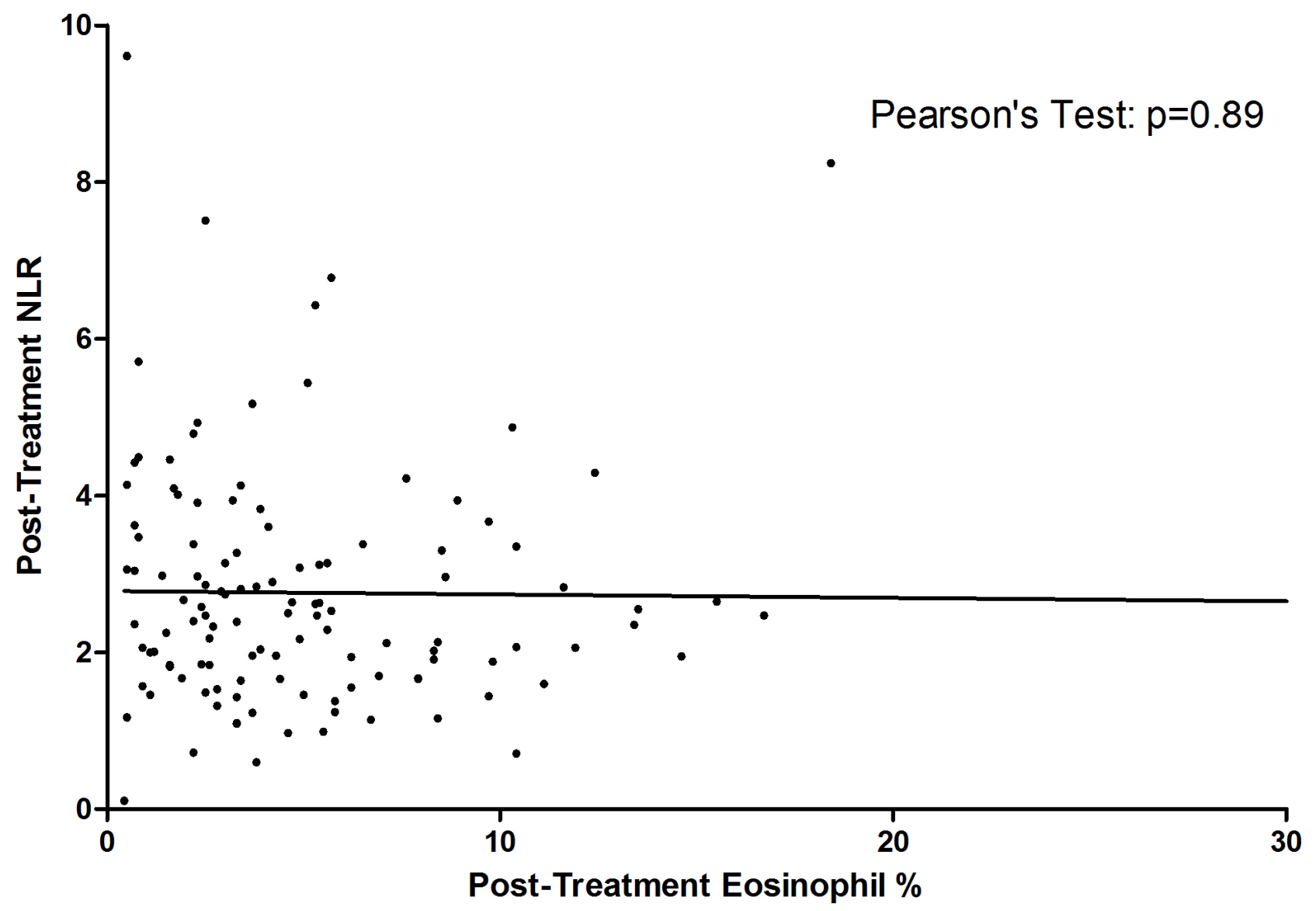

Figure 4: Pearson's test for post-treatment NLR and Post-treatment eosinophil percentage. 
Table 4: Comparison of MSKCC and Heng's Model and their modified models

\begin{tabular}{|c|c|c|c|c|c|c|c|c|c|}
\hline & \multicolumn{4}{|c|}{ MSKCC Model } & \multicolumn{5}{|c|}{$\begin{array}{l}\text { Post-treatment Eosinophil modified MSKCC } \\
\text { Model }\end{array}$} \\
\hline & $\begin{array}{l}\text { Patients } \\
\text { (No.) }\end{array}$ & $\begin{array}{l}\text { 1-Year } \\
\text { Survival }\end{array}$ & $\begin{array}{l}\text { 2-Year } \\
\text { Survival }\end{array}$ & $\begin{array}{l}\text { Median } \\
\text { Survival }\end{array}$ & $\begin{array}{l}\text { Patients } \\
\text { (No.) }\end{array}$ & $\begin{array}{l}\text { 1-Year } \\
\text { Survival }\end{array}$ & $\begin{array}{l}\text { 2-Year } \\
\text { Survival }\end{array}$ & $\begin{array}{l}\text { Median } \\
\text { Survival }\end{array}$ & $\mathrm{p}$-value \\
\hline Favorable & 66 & $91.40 \%$ & $77.60 \%$ & 77.9 months & 99 & $93.70 \%$ & $76.20 \%$ & $\begin{array}{c}77.9 \\
\text { months }\end{array}$ & 0.756 \\
\hline Intermediate & 178 & $77.30 \%$ & $48.80 \%$ & 22.4 months & 140 & $70.20 \%$ & $38.60 \%$ & $\begin{array}{c}19.4 \\
\text { months }\end{array}$ & 0.121 \\
\hline \multirow[t]{3}{*}{ Poor } & 38 & $25.10 \%$ & $0.00 \%$ & 8.9 months & 33 & $22.60 \%$ & $0.00 \%$ & 8.8 months & 0.787 \\
\hline & \multicolumn{4}{|c|}{ Heng's Model } & \multicolumn{4}{|c|}{$\begin{array}{l}\text { Post-treatment Eosinophil modified Heng's } \\
\text { Model }\end{array}$} & \\
\hline & $\begin{array}{l}\text { Patients } \\
\text { (No.) }\end{array}$ & $\begin{array}{l}\text { 1-Year } \\
\text { Survival }\end{array}$ & $\begin{array}{l}\text { 2-Year } \\
\text { Survival }\end{array}$ & $\begin{array}{l}\text { Median } \\
\text { Survival }\end{array}$ & $\begin{array}{l}\text { Patients } \\
\text { (No.) }\end{array}$ & $\begin{array}{l}\text { 1-Year } \\
\text { Survival }\end{array}$ & $\begin{array}{l}\text { 2-Year } \\
\text { Survival }\end{array}$ & $\begin{array}{l}\text { Median } \\
\text { Survival }\end{array}$ & p-value \\
\hline Favorable & 55 & $86.60 \%$ & $75.70 \%$ & 77.9 months & 96 & $92.90 \%$ & $78.20 \%$ & $\begin{array}{c}77.9 \\
\text { months }\end{array}$ & 0.712 \\
\hline Intermediate & 158 & $82.20 \%$ & $55.20 \%$ & 31.1 months & 126 & $77.50 \%$ & $44.70 \%$ & $\begin{array}{c}21.9 \\
\text { months }\end{array}$ & 0.098 \\
\hline Poor & 69 & $41.30 \%$ & $13.70 \%$ & 10.3 months & 60 & $35.70 \%$ & $11.00 \%$ & 9.4 months & 0.707 \\
\hline
\end{tabular}

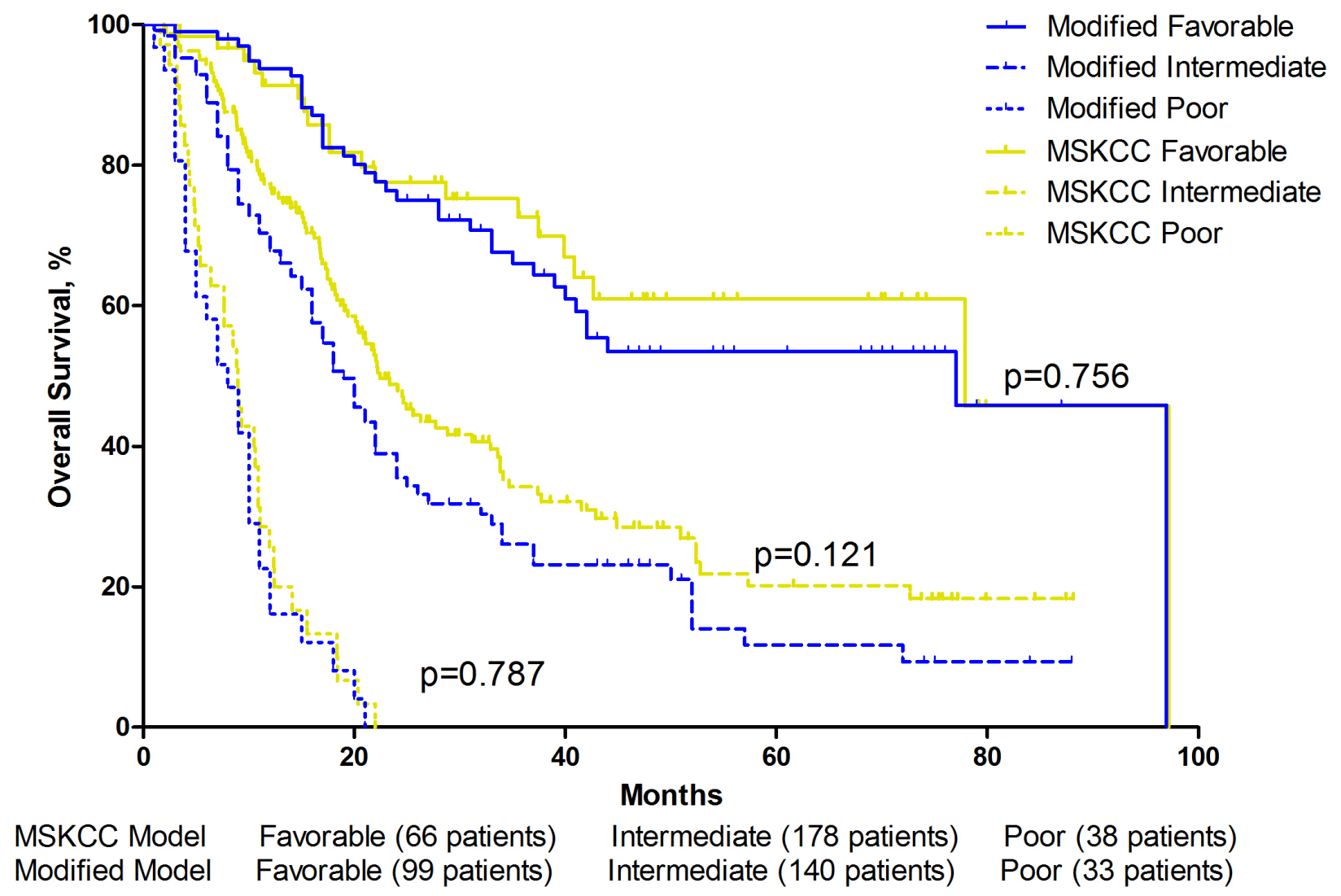

Figure 5: Overall survival by MSKCC Model and modified MSKCC Model risk groups. 
information of both neutrophils and lymphocytes, pretreatment NLR is an independent prognostic factor for patients with either non-metastatic or $\mathrm{mRCC}$ patients [6, 15]. Moreover, a decreased NLR after target therapy is often associated with a better prognosis [16]. Above all it is sure that host systemic inflammatory response may be altered by theraputic intervention. However, factors such as CRP and NLR are systemic inflammatory expressers, we still need another easily achived factor which can reveal host immune enhancement. Afterall we started this retrospective study focusing on Eo \%. Considering that a common toxicity of TKIs such as sunitinib is a decrease of blood cell counts, we chose sorafenib to minimize hematological toxicities associated bias.

Eosinophilic granulocytes (eosinophils) constitute less than $5 \%$ of the total white blood cells [17]. In the current study we defined a eosinophil cell count more than $5 \%$ as an elevation of Eo \% and found some association between post-treatment Eo \% (one-two months after target therapy) and mRCC outcome. The prognosis of patients who experienced an Eo \%elevation early after sorafenib treatment is better than those who did not. More CR and PR were achieved in the eosinophil elevated group indicating that it is a good interpreter of tumor response. To investigate whether the eosinophil change is subsequent to the changes in other hematologic parameters, we compaired post-treatment eosinophil \% status to post-treatment neutrophil count, lymphocyte and NLR, and found none statistical association.

To date, MSKCC model and Heng model are the two generally accepted prognostic scoring systems for survival of metastatic RCC patients [18, 19]. However, clinical parameters included in the two models were all pre-treatment parameters, they lack the capability to find patients who were congenital resistant to target agents neither can they provide enough prognostic information during the therapy. Thus lots of patients in the same stage turned out to be quite different in prognosis. During multivariate analysis of our data, we confirmed that post-treatment elevation of eosinophil, KPS, disease free interval, metastatic sites [20], low hemoglobin, serum calcium and lactate dehydrogenase were associated with adverse outcome independently. We didn't find any prognostic value of pre-treatment eosinophil. After we added post-treatment eosinophil to the MSKCC model and the Heng's model, we noticed that many patients were reclassified to lower risk groups with a minor change in median overall survival of each risk group. We then calculated the $\mathrm{C}$-index of the original models and the modified ones and finally observed that post-treatment eosinophil can enhance the predictive accuracy of the predictive models. These results finally indicated that posttreatment parameters can act as a good supplementary in predictive models.

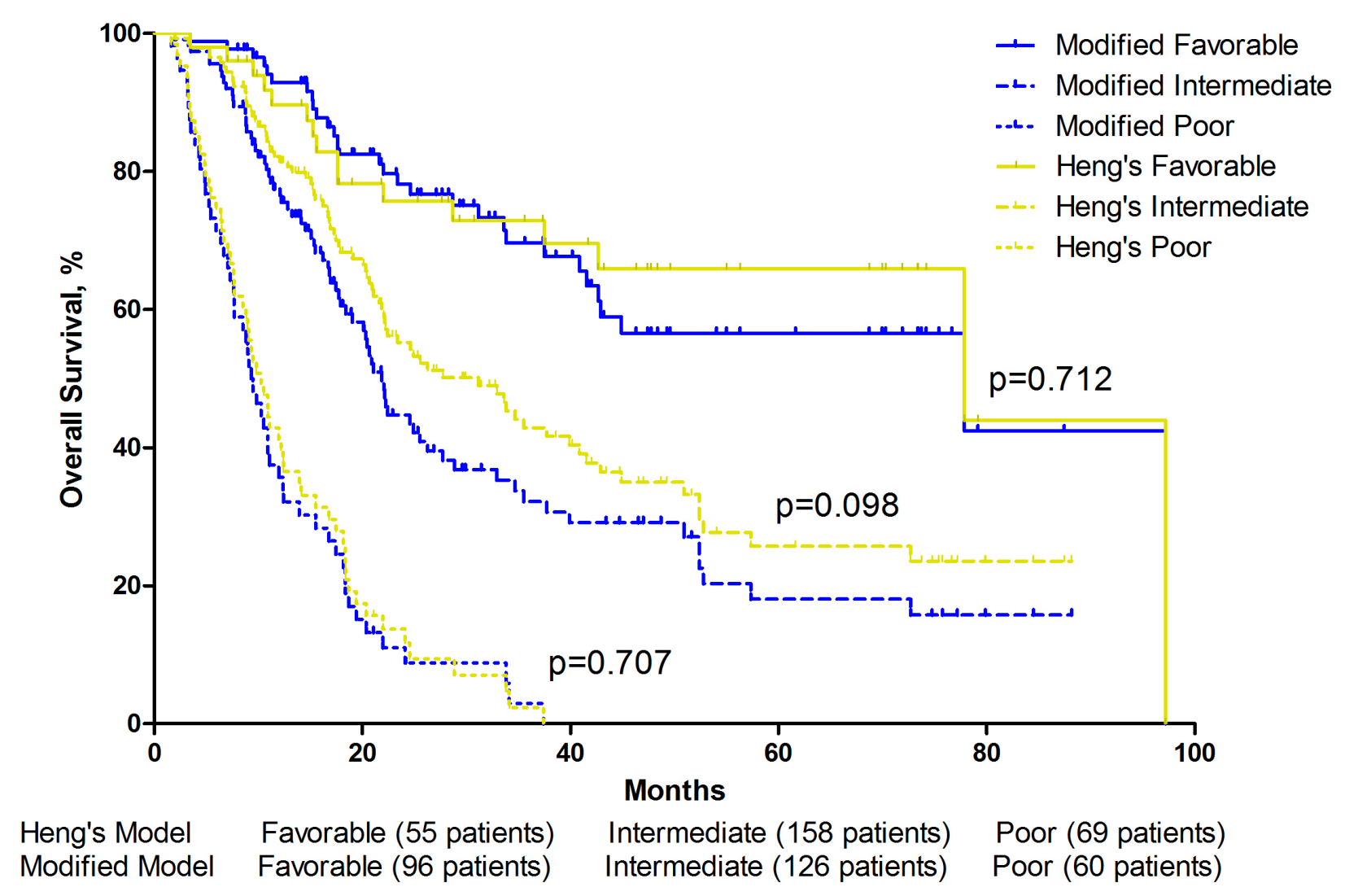

Figure 6: Overall survival by Heng's Model and modified Heng's Model risk groups. 
It remains unknown how the elevation of Eo \% is correlated to tumor response and survival in mRCC patients taking sorafenib. So far, results about eosinophil and RCC outcome were mainly from interferon-alpha $2 \mathrm{~b}$ (IFN) or interleukin-2 studies. Wersall first observed an eosinophil elevation in immunotherapy non-responders [21]. Moroni again said that blood eosinophilia predicts a poor response to immunotherapy in patients with advanced RCC [22]. However Lissoni indicated that lymphocyte and eosinophil mean number was significantly higher in patients with PR or SD than in the progressed ones [23], and in another study Rodgers et al found a significant correlation $(\mathrm{P}<$ or $=0.05)$ between eosinophil count and a better survival but not with clinical response [24]. None of the studies used Eo \% as a clinical parameter, so the results remain controversal. Yet in a mouse graft study, there is a substantial decrease in both tumorigenicity and tumor progression concomitant with an abundant tumor eosinophilia [25]. The elevation of Eo \% observed in our study may be due to tumor necrosis induced eosinophil migration, because it is believed that TATE may develop early and persist throughout tumor development [26, 27]. Indeed, apart from decreased CRP and NLR after treatment, we observed an elevated eosinphil percentage after treatment which indicated different mechanisms in predicting outcome.

There is still some limitations of our study. The sample size in our study is relatively small, we need larger multicenter results to validate our data. We retrospectively used patients undergoing sorafenib therapy, further studies for patients receiving sunitinib or other first line target therapies are needed. More molecular mechanisms about eosinophil and RCC outcome needed to be elucidated.

\section{MATERIALS AND METHODS}

\section{Patients and parameters}

Metastatic RCC patients treated with sorafenib during 2006 to 2015 in our institute were enrolled in the study. At least one measurable tumor lesion was required for each patient according to the Response Evaluation Criteria in Solid Tumors (RECIST, version 1.1) [28]. Pathology was confirmed by prior nephrectomy or tumor biopsy. Histological subtypes included clear-cell (cc) RCC, papillary RCC and ccRCC with sarcomatoid component. All patients were required to undergo blood tests at baseline and every two weeks after initiation of therapy to evaluate renal and hepatic function and check for blood cell counts. CT scans were repeated every eight weeks after initiation of sorafenib to evaluate tumor response. The study protocol was approved by our hospital's Institutional Review Board. All patients provided written informed consent to participate in the study.
The following were included for analysis as binary variables: Gender, age(cutoff $=64$ years old), karnofsky performance score(KPS)(cutoff=70), prior nephrectomy, disease free interval(cutoff $=12$ months), metastatic sites, prior immunotherapy, hemoglobin level(cutoff $=130 \mathrm{~g} / \mathrm{L}$ for male, $115 \mathrm{~g} / \mathrm{L}$ for female), calcium $($ cutoff $=2.5 \mathrm{mmol} / \mathrm{L}$ ), lactate dehydrogenase $($ cutoff $=450 \mathrm{U} / \mathrm{L})$, neutrophil count $\left(\right.$ cutoff $\left.=4.5 \times 10^{\wedge} 9 / \mathrm{L}\right)$, platelet $\operatorname{count}($ cutoff $=300$ $\left.\times 10^{\wedge} 12 / \mathrm{L}\right)$, pre-treatment Eo $\%($ cutoff $=5 \%$ ), posttreatment Eo \%(cutoff=5\%), MSKCC score [18], HENG score [19], post-treatment NLR(cutoff=3). The 5\% cut-off value of Eo \% is determined according to the reference interval given by Chinese Department of Health. Posttreatment Eo \% escalation was counted by the Eo \% foureight weeks after initiation of sorafenib. An Eo \%>5\% is defined as "Escalation of Eo \%".

The duration of OS was determined from the date of first dosage of sorafenib treatment to death or the date of the last follow-up visit for patients still alive. Disease control was defined as stable disease(SD), a partial response (PR) or a complete response(CR) according to RECIST criteria, the best tumor response will be recorded.

\section{Model reclassification}

As proposed by the NCCN guideline, the MSKCC Model and the Heng's Model are reliable prognostic models for survival prognosis. Hence we used those two models to evaluate the value of post-treatment Eo \% in clinical practice. Because an elevated post-treatment eosinophil showed significant prognistic value during the study, and a post-treatment parameter is different from those existing pre-treatment ones(such as KPS, calcium, hemoglobin et al.), we assume the elevation of posttreatment eosinophil can neutralize one of the adverse factors from those prognostic models. For example, if a patient have three adverse factors from Heng's model and then he experienced elevated eosinophil after treatment, he will be counted as having 3-1=2 factors in a modified Heng's model. On the other hand, if a patients have 0 adverse factors at the first time, he will still be counted as having zero factors in a modified Heng's model no matter having an elevated eosinophil or not.

\section{Statistical analyses}

Continuous data are presented as median (range) and binary data are presented as proportions. Association between variables was evaluated on the basis of the chi-square test. Pearson's test was used to determine the association between post-treatment NLR and Posttreatment Eo \%. The Kaplan-Meier method was used to determine overall survival rate. Overall survival rates were compared using the log-rank test. Predictive parameters were assessed in a Cox proportional hazard model, and odds ratios with $95 \%$ confidence intervals were calculated. 
The predictive accuracy of the model was evaluated by the concordance index(C-index $)$, which is the area under the receiver operating characteristic curve for censored data, in which a value of 0.5 indicates no predictive discrimination, and a value of 1 represents a perfect ability to separate patients [29]. The C-index analysis was calculated by using the R software. All other analyses were conducted using SPSS 20.0 software (IBM, Chicago, IL, USA). P values were two-tailed and a $\mathrm{P}<0.05$ was considered to indicate statistical significance.

\section{ACKNOWLEDGMENTS}

Author contributions: Hong-Kai Wang and HaiLiang Zhang had full access to all of the data in the study and takes responsibility for the integrity of the data and the accuracy of the data analysis.

Acquisition of data: Hai-Liang Zhang.

Study concept and design: Hai-Liang Zhang and Hong-Kai Wang.

Manuscript Writing: Hong-Kai Wang.

Statistical analysis:Hong-Kai Wang, Wei-Jie Gu and Yao Zhu.

Revision of the manuscript for intellectual content: FangNin Wan, Bo Dai, Guo-Hai Shi.

Correspondence: Ding-Wei Ye and Hai-Liang Zhang.

\section{CONFLICTS OF INTEREST}

There are no conflicts of interest disclosures from any authors.

\section{FUNDING/SUPPORT}

This work was supported by grants from the National Natural Science Foundation of China (No. 81202004 and N0.81472377).

\section{REFERENCES}

1. Motzer RJ, Hutson TE, Tomczak P, Michaelson MD, Bukowski RM, Rixe O, Oudard S, Negrier S, Szczylik C, Kim ST, Chen I, Bycott PW, Baum CM, et al. Sunitinib versus interferon alfa in metastatic renal-cell carcinoma. N Engl J Med. 2007; 356: 115-124.

2. Escudier B, Eisen T, Stadler WM, Szczylik C, Oudard S, Siebels M, Negrier S, Chevreau C, Solska E, Desai AA, Rolland F, Demkow T, Hutson TE, et al. Sorafenib in advanced clear-cell renal-cell carcinoma. N Engl J Med. 2007; 356: 125-134.

3. Motzer RJ, Escudier B, Oudard S, Hutson TE, Porta C, Bracarda S, Grunwald V, Thompson JA, Figlin RA, Hollaender N, Urbanowitz G, Berg WJ, Kay A, et al. Efficacy of everolimus in advanced renal cell carcinoma: a double-blind, randomised, placebo-controlled phase III trial. Lancet. 2008; 372: 449-456.

4. Interferon-alpha and survival in metastatic renal carcinoma: early results of a randomised controlled trial. Medical Research Council Renal Cancer Collaborators. Lancet. 1999; 353: 14-17.

5. Yang JC, Sherry RM, Steinberg SM, Topalian SL, Schwartzentruber DJ, Hwu P, Seipp CA, Rogers-Freezer L, Morton KE, White DE, Liewehr DJ, Merino MJ, Rosenberg SA. Randomized study of high-dose and lowdose interleukin-2 in patients with metastatic renal cancer. J Clin Oncol. 2003; 21: 3127-3132.

6. Keizman D, Ish-Shalom M, Huang P, Eisenberger MA, Pili R, Hammers H, Carducci MA. The association of pretreatment neutrophil to lymphocyte ratio with response rate, progression free survival and overall survival of patients treated with sunitinib for metastatic renal cell carcinoma. Eur J Cancer. 2012; 48: 202-208.

7. Saito K, Tatokoro M, Fujii Y, Iimura Y, Koga F, Kawakami $\mathrm{S}$, Kihara K. Impact of C-reactive protein kinetics on survival of patients with metastatic renal cell carcinoma. Eur Urol. 2009; 55: 1145-1153.

8. Davis BP, Rothenberg ME. Eosinophils and cancer. Cancer Immunol Res. 2014; 2: 1-8.

9. Gatault S, Legrand F, Delbeke M, Loiseau S, Capron M. Involvement of eosinophils in the anti-tumor response. Cancer Immunol Immunother. 2012; 61: 1527-1534.

10. Lucca I, de Martino M, Hofbauer SL, Zamani N, Shariat $\mathrm{SF}$, Klatte T. Comparison of the prognostic value of pretreatment measurements of systemic inflammatory response in patients undergoing curative resection of clear cell renal cell carcinoma. World J Urol. 2015;

11. Riemann D, Hase S, Fischer K, Seliger B. Granulocyte-todendritic cell-ratio as marker for the immune monitoring in patients with renal cell carcinoma. Clin Transl Med. 2014; 3: 13.

12. Donskov F, von der Maase H. Impact of immune parameters on long-term survival in metastatic renal cell carcinoma. J Clin Oncol. 2006; 24: 1997-2005.

13. Saroha S, Uzzo RG, Plimack ER, Ruth K, Al-Saleem T. Lymphopenia is an independent predictor of inferior outcome in clear cell renal carcinoma. J Urol. 2013; 189: 454-461.

14. Yasuda Y, Saito K, Yuasa T, Kitsukawa S, Urakami S, Yamamoto S, Yonese J, Takahashi S, Fukui I. Prognostic impact of pretreatment C-reactive protein for patients with metastatic renal cell carcinoma treated with tyrosine kinase inhibitors. Int J Clin Oncol. 2013; 18: 884-889.

15. Ohno Y, Nakashima J, Ohori M, Hatano T, Tachibana M. Pretreatment neutrophil-to-lymphocyte ratio as an independent predictor of recurrence in patients with nonmetastatic renal cell carcinoma. J Urol. 2010; 184: 873-878. 
16. Park $\mathrm{YH}, \mathrm{Ku} \mathrm{JH}$, Kwak C, Kim HH. Post-treatment neutrophil-to-lymphocyte ratio in predicting prognosis in patients with metastatic clear cell renal cell carcinoma receiving sunitinib as first line therapy. Springerplus. 2014; 3: 243 .

17. Andersen CL, Siersma VD, Hasselbalch HC, Lindegaard $\mathrm{H}$, Vestergaard H, Felding P, de Fine Olivarius N, Bjerrum OW. Eosinophilia in routine blood samples as a biomarker for solid tumor development - A study based on the Copenhagen Primary Care Differential Count (CopDiff) Database. Acta Oncol. 2014; 53: 1245-1250.

18. Mekhail TM, Abou-Jawde RM, Boumerhi G, Malhi S, Wood L, Elson P, Bukowski R. Validation and extension of the Memorial Sloan-Kettering prognostic factors model for survival in patients with previously untreated metastatic renal cell carcinoma. J Clin Oncol. 2005; 23: 832-841.

19. Heng DY, Xie W, Regan MM, Warren MA, Golshayan AR, Sahi C, Eigl BJ, Ruether JD, Cheng T, North S, Venner $\mathrm{P}$, Knox JJ, Chi KN, et al. Prognostic factors for overall survival in patients with metastatic renal cell carcinoma treated with vascular endothelial growth factor-targeted agents: results from a large, multicenter study. J Clin Oncol. 2009; 27: 5794-5799.

20. Motzer RJ, Bukowski RM, Figlin RA, Hutson TE, Michaelson MD, Kim ST, Baum CM, Kattan MW. Prognostic nomogram for sunitinib in patients with metastatic renal cell carcinoma. Cancer. 2008; 113: 1552-1558.

21. Wersall JP, Masucci G, Hjelm AL, Ragnhammar P, Fagerberg J, Frodin JE, Merk K, Lindemalm C, Ericson $\mathrm{K}$, Kalin B, et al. Low dose cyclophosphamide, alphainterferon and continuous infusions of interleukin-2 in advanced renal cell carcinoma. Med Oncol Tumor Pharmacother. 1993; 10: 103-111.

22. Moroni M, Porta C, De Amici M, Quaglini S, Cattabiani MA, Buzio C. Eosinophils and C4 predict clinical failure of combination immunotherapy with very low dose subcutaneous interleukin-2 and interferon in renal cell carcinoma patients. Haematologica. 2000; 85: 298-303.

23. Lissoni P, Barni S, Tancini G, Andres M, Scardino E, Cardellini P, Frascaroli M, Ardizzoia A, Crispino S, Vicini $\mathrm{D}$, et al. [Immunotherapy with low-dose subcutaneous interleukin-2 in metastatic renal carcinoma]. [Article in Italian]. Arch Ital Urol Androl. 1993; 65: 123-128.

24. Rodgers S, Rees RC, Hancock BW. Changes in the phenotypic characteristics of eosinophils from patients receiving recombinant human interleukin-2 (rhIL-2) therapy. Br J Haematol. 1994; 86: 746-753.

25. Simson L, Ellyard JI, Dent LA, Matthaei KI, Rothenberg ME, Foster PS, Smyth MJ, Parish CR. Regulation of carcinogenesis by IL-5 and CCL11: a potential role for eosinophils in tumor immune surveillance. J Immunol. 2007; 178: 4222-4229.

26. Cormier SA, Taranova AG, Bedient C, Nguyen T, Protheroe C, Pero R, Dimina D, Ochkur SI, O'Neill K, Colbert D, Lombari TR, Constant S, McGarry MP, et al. Pivotal Advance: eosinophil infiltration of solid tumors is an early and persistent inflammatory host response. J Leukoc Biol. 2006; 79: 1131-1139.

27. Stenfeldt AL, Wenneras C. Danger signals derived from stressed and necrotic epithelial cells activate human eosinophils. Immunology. 2004; 112: 605-614.

28. Therasse P, Arbuck SG, Eisenhauer EA, Wanders J, Kaplan RS, Rubinstein L, Verweij J, Van Glabbeke M, van Oosterom AT, Christian MC, Gwyther SG. New guidelines to evaluate the response to treatment in solid tumors. European Organization for Research and Treatment of Cancer, National Cancer Institute of the United States, National Cancer Institute of Canada. J Natl Cancer Inst. 2000; 92: 205-216.

29. Harrell FE, Jr., Lee KL, Mark DB. Multivariable prognostic models: issues in developing models, evaluating assumptions and adequacy, and measuring and reducing errors. Stat Med. 1996; 15: 361-387. 